\title{
3 Research Square \\ Next of Kin, An Invisible Resource In The Drug \\ Treatment of Nursing Home Residents: A \\ Qualitative Study
}

Hege Therese Bell ( $\nabla$ hege.t.bell@ntnu.no)

Department of Clinical and Molecular Medicine

Helga Vaage

Apotek 1 Hagaløkka

\section{Research Article}

Keywords: Next of kin, Nursing Home, Drug Therapy, Nursing Home Residents, Primary Health Care, Qualitative Research

Posted Date: January 18th, 2022

DOI: https://doi.org/10.21203/rs.3.rs-1107776/v1

License: (c) (i) This work is licensed under a Creative Commons Attribution 4.0 International License.

Read Full License 


\section{Abstract}

Objective: Explore next of kin's perceptions of the ongoing drug treatment given to nursing home residents, and their perceptions of the collaboration with health personnel at the nursing home.

Design, setting and subjects: A qualitative study with ten next of kin to nursing home residents who participated in semi-structured individual interviews in Central and Southern Norway. The data were analysed thematically by using systematic text condensation.

Results: Next of kin express a trust towards the drug treatment given, however, the trust is fragile. There was an urge for information and of being in control, not necessarily with the aim to influence treatment but to know what happens to their loved ones. Due to long-lasting knowledge of the resident, they viewed themselves as the resident's advocate to ensure appropriate drug treatment. The collaboration between health personnel and next-of-kin were scarce and described as an "us-them" relationship. Next of kin perceived having to force an entry for dialogue and of health personnel being inaccessible and invisible.

Conclusion: Next of kin want to be informed about the ongoing drug treatment given to the resident, however, information given are scarce and delayed which affect the trust towards health personnel at the nursing home. Input from next of kin could be used to offer person-centered care, however, next of kin perceive their input often being ignored.

Implications: Effort must be put to unite expectations and seek a mutual understanding of which role next of kin should hold regarding information and collaboration about the ongoing drug treatment of the nursing home resident.

\section{Key Points}

Current awareness:

- Health personnel are by law obligated to give information about the resident's drug list and ongoing drug treatment to selected next of kin when obligations met

Main statements:

- Next of kin trust the drug therapy given to the resident at the nursing home, however, the trust is fragile

- Claiming long-lasting knowledge of the resident, next of kin view themselves as the resident's advocate to ensure appropriate drug therapy

- Next of kin want to be informed about the ongoing drug treatment given to the resident, however, the information given is scarce and delayed.

\section{Background}


Nursing home medicine is based on the individual nursing home resident's wishes and needs combined with what is defined as relevant treatment and the best possible care for the individual. For many residents, medical treatment requires a continuous search for the balance between curative treatment and symptom relief [1]. Elderly living in nursing homes is prone to multimorbidity. Polypharmacy the use of multiple drugs simultaneously is therefore common [2]. In the elderly, polypharmacy, is often associated with decreased quality of life due to hospitalizations, adverse drug events, falls, impaired functional capacity and cognitive impairment [3]. A focus on appropriate drug use to improve and retain quality of life is therefore of uttermost importance.

According to Norwegian law, next of kin is defined as the person the patient assign as their closest relative [4]. In nursing homes, the spouse or the resident's descendants often operates as next of kin. The extent of involvement of next of kin is closely related to the patient's need of medical treatment. Their role will by law, be more extensive when the elderly lives in nursing home where defined as patient. When the nursing home resident gives consent, or when defined as unable to consent, the defined next of kin is by law entitled to be informed about the resident's medical treatment and state of health [4]. This imply that health personnel are obligated to give information about the resident's drug list and ongoing drug treatment to the selected next of kin when obligations met. Interprofessional collaboration and in particular a good dialogue with the resident and his next of kin is therefore of uttermost importance when focusing on appropriate drug use in nursing homes [5].

Relatives are often an important resource for the nursing home resident. They often have good knowledge of the resident and can thus provide important information and clarify needs on behalf of the resident. It is also perceived as important for elderly patients to have someone who will speak on their behalf and stand up for them [6]. Physicians find it difficult to alter and discontinue drug treatment in the elderly, especially when not having all information about the patient [7]. Next of kin was therefore perceived as someone who could help to gain better insight before making a decision, especially for patient living in nursing homes. There are, however, relatives who want a more active treatment than the patient himself or the physician [8].

There are studies focusing on how relatives and health personnel collaborate at the end of life [8, 9], however, the knowledge of how next of kin perceive the consecutive medical treatment of the nursing home resident and their perception of the collaboration with the health personnel during the whole residential stay is scarce. The aim of the study was therefore to explore next of kin's perceptions of the ongoing drug treatment given to nursing home residents, and their perceptions of the collaboration with health personnel at the nursing home.

\section{Methods}

We conducted a qualitative study based on ten individual semi-structured interviews of next of kin to nursing home residents in Central Norway during November 2018 to March 2019. The research project was approved by the Norwegian Centre for Research Data, NSD, who declared that the study fulfilled all 
requirements for data management and data protection thereby safeguarding privacy in agreement with regulations (\# 696326). In order to enhance comprehensive and explicit reporting of the study, the COREQ checklist [10] was used as a guide.

\section{Setting}

In Norway, the municipalities are responsible for social welfare and health care for all inhabitants, including those living in nursing homes. In 2019, there were about 39466 nursing home beds distributed in 942 institutions where private institutions counted for $10,2 \%$. The majority of beds $(81,3 \%)$ were longterm [11].

In 2011, the Norwegian nursing home resident was 84 years in average and three out of four residents were 80 years or older [12] and half of the Norwegian population live in nursing homes when they pass [11]. The majority of residents are women occupying more than $70 \%$ of the nursing home beds [12]. The nursing home patients in the area of the study used 9,8 drugs on average with a variation of 0 to 30 different drugs [13]. Part-time contracted general practitioners most commonly provide the medical services in nursing homes [14], however, number of full time nursing home physicians employed by the muncicpality is raising.

\section{Informants and data collection}

The aim was to include a purposive sample of selected next of kin of nursing home residents with variation in age, gender and kinship. Informants were recruited through nursing homes where information about the study were available for next of kin on the bulletin board when visiting the nursing home. In addition, information about the study was distributed to members of the user participation board for nursing homes in the municipality, and an advert about the study was also put in the region's main newspaper.

All interviews were conducted in a room at the university, except one which was carried out by telephone. The interviews lasted from 21 to 43 minutes with an average of 34 minutes and were led by the second author who is both a sociologist and a pharmacist with long experience of talking with people. An interview guide with open-ended questions focusing on the following themes was used; perceptions of the ongoing medical treatment received by their relative, reflections on their entitled rights as next-of-kin regarding information and perceived collaboration with the health personnel at the nursing home (Supplementary material.)

\section{Data analysis}

The interviews were digitally recorded and transcribed verbatim. They were analysed thematically using the method of systematic text condensation [15], according to an iterative four-step process. In the first step, both authors read a selection of the transcripts to identify preliminary themes, which were discussed. In the second step, the transcripts were searched in detail to identify meaning units, which were sorted under preliminary themes. In the third step, the meaning units were arranged into subthemes. 
In all these steps the preliminary themes were adjusted. Then a narrative condensate was made of the meaning units sorted under each theme and subtheme. In the last step, an analytic text was produced based upon each theme and subtheme. The themes and the analysis were discussed among the authors several times and the analysis were also discussed during the defence of the master thesis with and extended research group. During the whole process, the authors went back to the original transcripts to ensure that the analysis was based upon them. Disagreements were discussed until conformity.

\section{Results}

A total of ten next-of-kin were interviewed, eight women and two men, see Table 1.

Table 1

Informants

\begin{tabular}{|llllll|}
\hline Informant & Gender & Age (y) & Relation & Age resident $(y)$ & Length of stay (months) \\
\hline 1 & F & 46 & Daughter & 65 & 36 \\
\hline 2 & F & 88 & Wife & 92 & 36 \\
\hline 3 & F & 55 & Daugther & 85 & 30 \\
\hline 5 & F & 50 & Daugther & 74 & 60 \\
\hline 6 & M & 70 & Husband & 70 & 9 \\
\hline 7 & F & 65 & Daughter & 96 & 48 \\
\hline 8 & F & 65 & Daugther & 97 & 36 \\
\hline 9 & F & 60 & Daugther & 89 & 6 \\
\hline 10 & M & 46 & Son & 73 & 9 \\
\hline & F & 52 & Daugther & 80 & 18 \\
\hline
\end{tabular}

One resident had passed only weeks before the interview. Four main themes were identified; Expressed but fragile trust, In need of an overview and control, The resident's advocate and Us-them. Main themes and sub-themes are outlined in table 2 .

Table 2 Themes and subthemes 

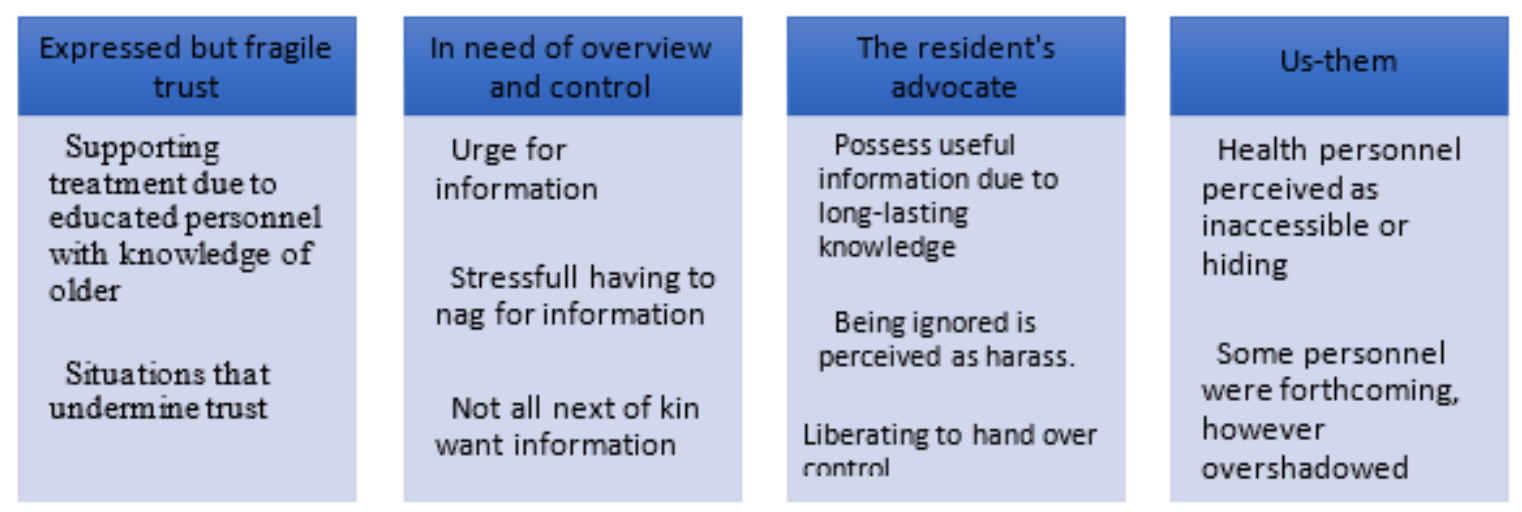

\section{Expressed but fragile trust}

It was common to have an underlying trust in health personnel at the nursing home and therefor to trust the decisions made. In spite of occasional negative media coverage on inappropriate drug use in elderly living in nursing homes, the informants expressed that people in general didn't have to worry about the drug therapy executed. When asked, the reason given was health personnel being educated professionals with knowledge of the older. Common features when content with the ongoing drug treatment were; the resident to have an unaltered drug list for a long period of time, the drugs on the list was initiated by a specialist at the hospital or absence of decline in the underlying condition when drugs being ceased.

There were, however, specific situations that undermined the trust, revealing the existing trust to be fragile such as experiencing a genuine deviation or something they personally perceived as an error. Other examples were, finding out by chance about extensive drug use or discover a specific medicine they knew had been terminated years prior to the nursing home admission. These episodes made the relatives question the ongoing drug treatment, and whether appropriateness was considered.

'... and I as a layman do not have the prerequisite to know what she really needs. So, I have to trust the personnel at the nursing home and that the physician really follows up on her. I have to say that I feel like, can I rely on that?' (Husband)

In need of overview and control

The majority of the interviewees wanted to be informed about the residents ongoing drug treatment, such as which drugs the relative was on and why. The urge for information was explained as a desire to know what happened with their loved ones, not necessarily as a tool to influence the treatment. There was a wish for more information than they received today and preferably as early in the process as possible. When asked how they wanted the information given they suggested annual or regular meeting with the personnel where drug therapy was presented and reviewed. There were interviewees who recalled an information meeting during or shortly after the admission to the nursing home, however, they could not recall any information given. 
When information was given and explained they found it reassuring. This was especially the case when thorough information was given when initiating or ending a drug treatment. These decisions were easier to accept contrary to receiving no or delayed information. These incidents were however rare, and the interviewees emphasized they got more information about the purpose of each drug when the resident were hospitalised. At the hospital they experienced several drugs to be ceased and the cessation explained and justified. At the nursing home they had to nag for information which they found very stressful, and when information finally was given it came too late.

'I would like to be more involved, up-front, without having to ask for information.' (Son)

There were, however, interviewees that did not frequently requested information. When asked to give grounds they said they were aware of the health personnel's high workload, and by imposing more duties it could affect the care given to the resident. It was better to ask questions when needed since too much information also could lead to unnecessary concern. Respecting the resident's right to privacy was also highlighted.

The resident's advocate

The next-of-kin perceived themselves as a resource on behalf of the resident. This was particularly important for residents who was unable to express their own needs. Next-of-kin possessed useful information relevant for the drug treatment due to long-lasting knowledge of the resident prior to the nursing home admission. In addition, when frequently visiting they were able to register subtle changes in behaviour. When asked to exemplify they mentioned; identify needs, identify drugs missing in transition of care and input on specific drugs tried out prior to the nursing home without effect or which was not preferable.

'Since I visit her quite often and have known her my whole life (laughter), I feel I do have some input that can be valuable.'(Son)

When expressing their concerns their experiences varied from those perceiving a low threshold for questions and to be taken seriously to those being brushed aside. The latter group spoke of suggestions being ignored such as asking for ointment instead of eye droplets when experiencing challenge of adherence or when suggesting physical activity as an alternative to medical treatment. Not to be heard was perceived as an enormous harass. The nagging exhausted them and left them with the feeling of being worn out.

'I did not find it difficult to bring the subject to the physician, but the way she responded was uncomfortable. She kind of brushed it aside without being willingly to try anything...' (Daughter)

In spite of the majority wanting to be actively involved in the drug treatment given there were interviewees who thought it was liberating to relinquish the responsibility to someone else, and therefore chose to take a non-active role. 
The interaction between health personnel and next-of-kin was in general described as an "us-them" relationship. This was based on having to force an entry for dialogue when wanting to discuss a subject. When asked to elaborate; the interviewees spoke of health personnel who were inaccessible and invisible or being met with excuses and various explanations perceived as rationalization. An exception was at end of life where dialogue was tight and in advance.

'The whole experience of the nursing home is perhaps it is more of a workplace for the staff than a home for those living there.' (Daughter)

There was a specific wish for the physician to be more accessible. With only one day present during weekdays the physician was hard to reach. A low threshold for a drop-in conversation was desired. The other health personnel on duty were occasionally perceived as hiding. There were, however, interviewees who stressed that they did not want to bother the physician unless it was really important and who were afraid of being perceived as someone wanting to double check the decisions made.

The next-of-kin were, however, able to give grounds to why they might perceive health personnel as inaccessible and invisible. Their visits were most likely during weekends or in the afternoon when staffing was lower, and they observed shortage of staff with only one nurse on duty per ward. Additionally, it was emphasized that there were personnel who were forthcoming, however, they were often overshadowed.

\section{Discussion}

The interviewees expressed a trust towards the drug treatment given, however, the trust was fragile. There was an urge for information and of being in control, and they viewed themselves as the resident's advocate to ensure appropriate drug treatment. The collaboration between health personnel and next-ofkin were scarce except during the resident's end of life. Below we discuss strength, limitation, and interpretations of these findings.

Strength and weakness

The study got high information power [16] due to a narrow aim and a diversity of eligible informants regarding gender, kinship and age. In addition, the second author who conducted the interviews is both a sociologist and a pharmacist with long experience of talking with people leading to rich interviews. It can't, however, be ruled out that mainly interviewees with interest in the subject were recruited thereby limiting the diversity of perspectives. There were, however, confirmations of the findings in the literature hereby ensuring the transferability [17-19]. Both authors performed the analysis, and the results were later discussed in an extended research group to ensure validity. First author is a municipality pharmacist with experience of qualitative methods. This contributed to a diversity of perspectives.

Information about ongoing treatment - too little too late 
A good collaboration between relatives and health personnel is dependent on mutual openness where both parties get to discuss desired topics and where health personnel is good at sharing knowledge and thoughts with the relatives [20]. When the resident gives or when unable to give consent the selected next of kin is by Norwegian law entitled to be informed about the resident's medical treatment and state of health [4]. Except from at end-of-life our informants only spoke of being well informed when the resident was hospitalized. At the hospital, information about the drugs indication and side effects was given unsolicited contrary to the nursing home. Experiencing this openness at the hospital might be the reason why cessation of medicines was more accepted opposed to the nursing home [18]. Several findings in our study indicate that next of kin receive too little information too late about the resident's ongoing drug treatment.

The next of kin spoke of a need for overview and control and therefore anticipated consecutive information about which drugs the resident used and their purpose. Decisions made was easier to accept when explained and justified. Then to experience the need to nag for information and to force an entry for dialogue with staff was exhausting. This is in line with others who found relatives receiving limited information when acting passive $[17,18]$. Expectations towards nursing home personnel were high, and they anticipated nursing home personnel to see their need of information [9]. A well-informed relative is, however, in contrast to literature showing nurses to perceive their task to inform relatives as timeconsuming and of low priority [21]. Other tasks were perceived as more important. Physicians also perceive the task to inform next of kin as time consuming and as an obstacle for providing the best care for the elderly $[8,22]$. Our findings therefor imply next of kin to have an expectation of being a member of a coadjutant team of information flow in contrast to health personnel holding a two-part focus including only themselves and the resident. This is in line with others finding relatives to feel invisible and excluded [23].

Lack of information could be due to lack of meeting points. The interviewees in our study spoke highly of both scheduled appointments but also the ability to knock on the door for drop-in conversations. The former is line with others who found relatives to prefer scheduled appointments while nurses has been found to be more open for spontaneous exchange of information [24]. The latter, however, was difficult for our informants due to staff being perceived as inaccessible and invisible. There might also be dissimilar grounds for why exchange of information about the ongoing drug treatment should take place. The urge for information was by the interviewees explained as a desire to know what happened with their loved ones, not necessarily with the aim to influence the treatment. This might not be fully understood by health personnel who not necessarily are interested in such an interference. Health personnel has claimed, by virtue of being experts, that they should be able to provide care for the elderly without interference from the relatives [25] and to be trusted in doing their job properly [24]. Employees has also been found to find it difficult to know how much information to share about the patients with the relatives [24]. The interviewees did acknowledge the health personnel's expertise, however, if they felt uninformed the trust faded. 
The relatives voice in this study was however not unanimous. There were, interviewees who stated great confidence in the health personnel and therefore chose to take a non-active role. These informants also spoke of heavy responsibility prior to the nursing home admission and then to be able to relinquish the responsibility to someone else was perceived as emancipatory, as found by others [23]. In addition, there were interviewees who reflected upon the possibility that too much information about the medicines and their side effects could leave relatives anxious and concerned. A common feature of those who trusted the health personnel was an absence of episodes with conflict of interest. There were, however, informants in our study who in spite of their rights emphasized the resident's right to privacy. An important task for the nursing home health personnel is therefore to get to know the next of kin to be able to adjust the information.

Person-centred care - next of kin an invisible resource

Physicians have declared they sometimes need to act without having access to the whole clinical picture [7]. Vital information given by next of kin, providing them with better insight before making a decision, was therefore appreciated when caring for nursing home patients. Additionally it has been found that the majority of patients want their next-of-kin to be informed and involved in decision-making processes [26]. Person-centered care is key to be able to offer high quality care in nursing homes [27] and is also relevant when considering appropriate drug use in the elderly where psychological and social determinants should be considered in addition to the more traditional clinical and physical determinants [28]. The informants in this study gave many examples on how they could contribute to person-centered care such as to identify needs and subtle changes in behaviour, identify drugs missing in the transition between levels of care and input on specific drugs that had been tried prior to the nursing home without effect or which was not preferable. To perceive themselves as a resource on behalf of the resident, especially residents unable to express their own needs, is in line with others who found relatives to undertake a role as guardian when perceiving dissonance in the residents' health or medication [19]. Relatives has also been perceived, due to their knowledge of the resident, as a resource to reduce hospital admissions in nursing homes [29]. This is in contrast to the findings in this study where interviewees spoke of input being brushed aside or ignored. An example was the informant who repeatedly had expressed concern about the resident drinking too little, and who claimed the hospital admission could have been avoided if the health personnel had listened.

There were, however, interviewees who admitted having difficulties in distinguishing between old age, illness and side effects of drugs. Therefor admitting being a bit on the edge, and to interpret signals in the worst sense and as side effects of drugs. They hereby admitted to not necessarily possesses the whole truth about the situation. Health personnel has emphasized that the next-of-kin might have known the patient as he/she was before and therefor do not necessarily know what is the best for the resident today [25] and that this therefore must be taken in to account when inviting the next of kin in to the decisionmaking process. Health personnel should take time to explain natural decline and how this might affect appropriate drug use to the relatives, since decisions that were thoroughly explained and justified were easier to accept. 


\section{Conclusion}

Next of kin want to be informed about the ongoing drug treatment given to the resident, however, information given are scarce and delayed which affect the trust between the parties. Input from the next of kin could be used to offer person-centered care but are often ignored by the health personnel. Input being rejected is, however, accepted as long as it is thoroughly explained and justified. In spite of regulations, there seem to be incompatible expectations to what the role of next of kin entail when it comes to information about the ongoing drug treatment of the resident.

Effort must be given to unite expectations and seek a mutual understanding of what the role of next of kin should hold regarding information and collaboration about the ongoing drug treatment of the resident. To achieve this, health personnel ought to be enlightened about next of kin's legal rights, but also acknowledge their personal needs and preferences.

\section{Declarations}

\section{Ethics approval and consent to participate}

The Regional Committees for Medical and Health Research Ethics in Central Norway assessed the study (2018/1685) and concluded the study was granted an exemption from requiring ethics approval. Participants were provided with written and oral information about the study and informed that they could withdraw at any time. Written consent was obtained from the participants before the interviews were conducted. In the case of the home care resident, consent was obtained for those who were able (2/10), otherwise the next of kin consented on behalf of both parts. To protect the participants' anonymity, no personal information was disclosed. The methods were carried out in accordance with Declaration of Helsinki.

\section{Consent for publication}

Not applicable

\section{Availability of data and materials}

The data for this study consist of written transcripts in Norwegian. The letter of consent and the transcripts constituting the data in the current study are available from the corresponding author on reasonable request.

\section{Competing interests}

The authors report no conflict of interest. The authors alone are responsible for the content and writing of the paper. 


\section{Funding}

This study was supported by Norwegian University of Science and Technology, NTNU and is based upon a Master thesis in Pharmacy.

\section{Authors'contributions}

$\mathrm{HV}$ conducted the interviews in the study. Both authors analysed the data. HTB had the leading pen writing the manuscript which was based upon HV's master thesis. HTB designed the study and both authors contributed to the content in the manuscript. Both authors read and approved the final manuscript.

\section{Acknowledgements}

We are in debt to all informants for sharing their time and insight.

\section{References}

1. Schols JM, Crebolder HF, van Weel C. Nursing home and nursing home physician: the Dutch experience. J Am Med Dir Assoc. 2004;5(3):207-12.

2. Tommelein E, Mehuys E, Petrovic M, Somers A, Colin P, Boussery K. Potentially inappropriate prescribing in community-dwelling older people across Europe: a systematic literature review. Eur J Clin Pharmacol. 2015;71(12):1415-27.

3. Turner JP, Edwards S, Stanners M, Shakib S, Bell JS. What factors are important for deprescribing in Australian long-term care facilities? Perspectives of residents and health professionals. BMJ Open. 2016;6(3):e009781.

4. Lov om pasient- og brukerrettigheter LOV-2020-06-19-79 (1999). https://lovdata.no/lov/1999-07-0263/§3-3 (Accessed 22.02.2021)

5. Maher RL, Hanlon J, Hajjar ER. Clinical consequences of polypharmacy in elderly. Expert Opin Drug Saf. 2014;13(1):57-65.

6. Dyrstad DN, Storm M. The Role of Next of Kin in Care Transitions. In: Aase K, Waring J, Schibevaag L, editors. Researching Quality in Care Transitions: International Perspectives. Cham: Springer International Publishing; 2017. p. 87-101.

7. Bell HT, Steinsbekk A, Granas AG. Factors influencing prescribing of fall-risk-increasing drugs to the elderly: A qualitative study. Scand J Prim Health Care. 2015;33(2):107-14.

8. Romøren M, Pedersen R, Førde R. How do nursing home doctors involve patients and next of kin in end-of-life decisions? A qualitative study from Norway. BMC Med Ethics. 2016;17:5.

9. Fosse A, Schaufel MA, Ruths S, Malterud K. End-of-life expectations and experiences among nursing home patients and their relatives-a synthesis of qualitative studies. Patient Educ Couns. 
2014;97(1):3-9.

10. Tong A, Sainsbury P, Craig J. Consolidated criteria for reporting qualitative reserch (COREQ): a $32-$ item checklist for interviews and focus groups. International Journal for Quality in Health Care, 2007;19(6):349-357 https://doi.org/10.1093/intqhc/mzm042

11. SSB SN. Sjukeheimar, heimetenester og andre omsorgstenester 2020 Available from: https://www.ssb.no/helse/statistikker/pleie/aar. (Accessed 23.03.21)

12. SSB SN, Jorun Ramm. Eldres bruk av helse og omsorgstjenester. 2011. Available from: https://www.ssb.no/helse/artikler-og-publikasjoner/_attachment/125965?_ts=13f8b5b (Accessed 23.03.2021)

13. Soraas IA, Staurset HB, Slordal L, Spigset O. [Drug-drug interactions in nursing home patients]. Tidsskr Nor Laegeforen. 2014;134(10):1041-6.

14. Ruths S, Sorensen PH, Kirkevold O, Husebo BS, Kruger K, Halvorsen KH, et al. Trends in psychotropic drug prescribing in Norwegian nursing homes from 1997 to 2009: a comparison of six cohorts. Int J Geriatr Psychiatry. 2013;28(8):868-76.

15. Malterud K. Systematic text condensation: a strategy for qualitative analysis. Scand J Public Health. 2012;40(8):795-805.

16. Malterud K, Siersma VD, Guassora AD. Sample Size in Qualitative Interview Studies: Guided by Information Power. Qual Health Res. 2016;26(13):1753-60.

17. Ekström K, Spelmans S, Ahlström G, Nilsen P, Alftberg $\AA$, Wallerstedt B, et al. Next of kin's perceptions of the meaning of participation in the care of older persons in nursing homes: a phenomenographic study. Scand J Caring Sci. 2019;33(2):400-8.

18. Majerovitz SD, Mollott RJ, Rudder C. We're on the same side: improving communication between nursing home and family. Health Commun. 2009;24(1):12-20.

19. Helgesen AK, Larsson M, Athlin E. How do relatives of persons with dementia experience their role in the patient participation process in special care units? J Clin Nurs. 2013;22(11-12):1672-81.

20. Smeets CH, Smalbrugge M, Zuidema SU, Derksen E, de Vries E, van der Spek K, et al. Factors related to psychotropic drug prescription for neuropsychiatric symptoms in nursing home residents with dementia. J Am Med Dir Assoc. 2014;15(11):835-40.

21. Hertzberg A, Ekman S-L, Axelsson K. 'Relatives are a resource, but... Registered Nurses' views and experiences of relatives of residents in nursing homes. Journal of Clinical Nursing. 2003;12(3):43141.

22. Fried TR, Tinetti ME, lannone L. Primary care clinicians' experiences with treatment decision making for older persons with multiple conditions. Arch Intern Med. 2011;171(1):75-80.

23. Nakrem $S$, Hynne AB. Pårørende en betinget ressurs? En kvalitativ studie av pårørende til langtidsbeboere i sykehjem sine erfaringer av egen rolle. Tidsskrift for omsorgsforskning. 2017;3(3):165-75. 
24. Hertzberg A, Ekman SL. 'We, not them and us?' Views on the relationships and interactions between staff and relatives of older people permanently living in nursing homes. J Adv Nurs. 2000;31(3):61422.

25. Holmgren J, Emami A, Eriksson LE, Eriksson H. Being perceived as a 'visitor' in the nursing staff's working arena-the involvement of relatives in daily caring activities in nursing homes in an urban community in Sweden. Scand J Caring Sci. 2013;27(3):677-85.

26. Friis $P$, Førde R. Advance care planning discussions with geriatric patients. Tidsskr Nor Laegeforen. 2015;135(3):233-5.

27. Koren MJ. Person-centered care for nursing home residents: the culture-change movement. Health Aff (Millwood). 2010;29(2):312-7.

28. Todd A, Jansen J, Colvin J, McLachlan AJ. The deprescribing rainbow: a conceptual framework highlighting the importance of patient context when stopping medication in older people. BMC Geriatr. 2018;18(1):295.

29. Powell C, Blighe A, Froggatt K, McCormack B, Woodward-Carlton B, Young J, et al. Family involvement in timely detection of changes in health of nursing homes residents: A qualitative exploratory study. J Clin Nurs. 2018;27(1-2):317-27.

\section{Supplementary Files}

This is a list of supplementary files associated with this preprint. Click to download.

- Supplementarymaterial.docx 